\title{
Using green fluorescent protein to understand the mechanisms of G-protein-coupled receptor regulation
}

S.S.G. Ferguson

\section{Correspondence}

S.S.G. Ferguson

The John P. Robarts Research Institute

Departments of Physiology,

Pharmacology and Toxicology

University of Western 0 ntario

London, Ontario

Canada, N6A 5K8

Presented at the International Symposium: Biological Applications of Confocal Microscopy, Belo Horizonte, MG, Brasil, April 6-8, 1998.

Research supported by O ntario Heart and Stroke Foundation (No. NA-3349).

Received May 14, 1998 Accepted June 3, 1998
The John P. Robarts Research Institute and Departments of Physiology, Pharmacology and Toxicology, U niversity of W estern O ntario, London, O ntario, Canada

\section{Abstract}

G protein-coupled receptor (GPCR) activation is followed rapidly by adaptive changes that serve to diminish the responsiveness of a cell to further stimulation. This process, termed desensitization, is the consequence of receptor phosphorylation, arrestin binding, sequestration and down-regulation. GPCR phosphorylation is initiated within seconds to minutes of receptor activation and is mediated by both second messenger-dependent protein kinases and receptor-specific $\mathrm{G}$ proteincoupled receptor kinases (GRKs). Desensitization in response to GRK-mediated phosphorylation involves the binding of arrestin proteins that serve to sterically uncouple the receptor from its $\mathrm{G}$ protein. GPCR sequestration, the endocytosis of receptors to endosomes, not only contributes to the temporal desensitization of GPCRs, but plays a critical role in GPCR resensitization. GPCR down-regulation, a loss of the total cellular complement of receptors, is the consequence of both increased lysosomal degradation and decreased mRNA synthesis of GPCRs. While each of these agonist-mediated desensitization processes are initiated within a temporally dissociable time frame, recent data suggest that they are intimately related to one another. The use of green fluorescent protein from the jellyfish Aqueora victoria as an epitope tag with intrinsic fluorescence has facilitated our understanding of the relative relationship between GRK phosphorylation, arrestin binding, receptor sequestration and down-regulation.

\author{
Key words \\ - Arrestin \\ - Endocytosis \\ - Green fluorescent protein \\ - G protein-coupled receptors \\ - G protein-coupled receptor \\ kinases \\ - Resensitization
}

\section{Introduction}

G protein-coupled receptors (GPCRs) form the largest family of integral membrane receptors. These receptors are seven transmembrane-spanning proteins that respond to a wide variety of stimuli including light, odour, taste, hormones and neurotransmitters. Activation of a GPCR results in the modulation of intracellular second messenger levels and/or ionic conductances via the coupling of receptors to a wide variety of effector systems via heterotrimeric guanine nucleotide-binding proteins ( $\mathrm{G}$ proteins). Agonist activation of a GPCR induces the isomerization of the receptor to a "highaffinity" agonist-binding conformation catalyzing the exchange of GDP for GTP on the $G$ protein $\alpha$-subunit (1). This exchange of GDP for GTP allows the dissociation of the $\mathrm{G}_{\alpha}$-subunit from the $\mathrm{G}_{\beta \gamma}$-subunits, which when dissociated from one another regulate the activity of effector systems such as adenylyl cyclase and potassium channels.

Shortly following exposure to an agonist, GPCR responsiveness wanes as the conse- 
quence of receptor desensitization. Receptor desensitization plays an important physiological role by preventing overstimulation of GPCR signaling cascades which in the case of constitutively active mutant receptors leads to diseases such as retinal degeneration, precocious puberty and thyroid tumors (2-4). Moreover, receptor desensitization provides a mechanism by which GPCR-mediated signals from multiple cellular or hormonal inputs can be filtered into meaningful information. However, the up-regulation of proteins associated with GPCR desensitization has also been associated with diseases such as hypertension, congestive heart failure and drug dependence and tolerance (5-8). Consequently, a firm understanding of how the processes of receptor activation, desensitization and resensitization are related to one another is critical to the development of strategies aimed at ameliorating GPCR-related diseases. The present report overviews the current understanding of GPCR regulatory mechanisms and how green fluorescent protein (GFP) from the jellyfish Aqueora victoria is facilitating this understanding.

\section{Receptor desensitization}

\section{Phosphorylation}

The desensitization of GPCR responsiveness results as the culmination of several events including: the uncoupling of receptors from their heterotrimeric $G$ protein as the consequence of receptor phosphorylation, sequestration (endocytosis) of receptors to endosomes and down-regulation of the total cellular complement of receptors. While each of these processes is initiated by the exposure of receptors to agonist, they proceed at different rates and can be dissociated on this basis. Receptor/G protein uncoupling occurs in response to phosphorylation by both second messenger-dependent protein kinases (e.g., cAMP-dependent protein kinase, PKA) and receptor-specific $\mathrm{G}$ protein-coupled receptor kinases (GRKs) (9-11). GRK-phosphorylation of GPCRs occurs within seconds to minutes following the activation of a receptor by the agonist and promotes the binding of arrestin proteins. Arrestins when bound to receptors sterically interdict receptor/G protein interactions (12-15). Second messengerdependent protein kinase-mediated phosphorylation of GPCRs does not promote arrestin protein binding; rather, it is the second messenger-dependent protein kinase-mediated phosphorylation event itself that results in receptor desensitization. For example, in the case of the $\beta_{2}$-adrenergic receptor $\left(B_{2} A R\right)$, phosphorylation of a PKA consensus site in the third intracellular loop of this receptor is thought to sterically prevent the interactions between the receptor and its G protein (9). Both second messenger-dependent protein kinases and GRKs contribute to the agonistdependent desensitization of GPCRs. However, unlike GRKs, second messenger-dependent protein kinases exhibit the capacity (when activated) to indiscriminately phosphorylate receptors that have not been exposed to the agonist (9-11).

The GRK protein family of Ser/Thr kinases consists of six members which can be subclassified according to both sequence homology and functional similarity $(9-11,16)$ : 1) rhodopsin kinase (GRK1), 2) B-adrenergic receptor kinase 1 (ßARK1 or GRK2) and BARK2 (GRK3), 3) the GRK4 subfamily, comprised of GRK4, GRK5 and GRK6. In unstimulated cells GRK1, GRK2 and GRK3 are primarily localized to the cytosol and translocate to their agonist-activated plasma membrane-bound receptor targets. In contrast, GRK4, GRK5 and GRK6 exhibit substantial membrane localization in the absence of agonist activation of GPCRs. GRKs phosphorylate GPCRs at serine and threonine residues residing within the carboxylterminal tail (e.g., $B_{2} \mathrm{AR}$ ) or third intracellular loop (e.g., m2 muscarinic acetylcholine receptor, $\mathrm{m} 2 \mathrm{mAChR}$ ). The GRK protein structure can be subdivided loosely into three 
functional domains: an amino-terminal domain that is thought to be important for substrate recognition, a central catalytic domain and a variable carboxyl terminal domain critical for plasma membrane targeting $(9,16)$. Several distinct mechanisms for membrane targeting are utilized by GRKs. These mechanisms include farnesylation of a carboxyl-terminal CAAX motif (GRK1), pleckstrin homology $(\mathrm{PH})$ domain interactions with $\mathrm{G}$ protein $\beta_{\gamma}$-subunits (GRK2 and GRK3), palmitoylation of cysteine residues (GRK4 and GRK6) and electrostatic interactions between highly basic amino-terminal amino acids and membrane phospholipids (17-20). Recently, a combination of biochemical techniques used in conjunction with a GFP-tagged GRK2 has identified tubulin as a novel GRK substrate (21).

\section{Sequestration}

Receptor sequestration is initiated within the same time-course as phosphorylation but proceeds somewhat slower. The agonist-promoted sequestration of GPCRs to a "lightvesicular" or "endosomal" pool of membranes is also thought to contribute to the temporal desensitization of GPCRs by removing receptors to a compartment inaccessible to the agonist. However, the sequestration of receptors is not absolutely required for the manifestation of GPCR desensitization since treatments that block the endocytosis of GPCRs do not prevent GPCR desensitization $(22,23)$. Rather, receptor sequestration appears to play a more important role in the resensitization of GPCR responsiveness. This idea arose from the following observations: 1) after agonist stimulation $B_{2}$ ARs isolated from the light vesicular pool of membranes exhibit lower stoichiometry of phosphorylation (24), 2) pharmacological treatments that block receptor endocytosis and recycling also block receptor resensitization $(22,23)$ and 3) sequestration-defective mutants that desensitize but do not resensitize have been identified (25). Consequently, receptor sequestration is best described as a process involving the internalization of GPCRs to an endosomal compartment where they become dephosphorylated and recycled back to the plasma membrane in their pre-ligand exposed state. The precise endocytic mechanism by which GPCRs endocytose remains controversial as both clathrin-dependent and -independent mechanisms have been described. However, in the case of the $B_{2} \mathrm{AR}$, the prominent endocytic mechanism in many cell lines appears to be via clathrin-coated vesicles (26).

While the molecular mechanisms involved in the phosphorylation-dependent desensitization of GPCR responsiveness have been fairly well delineated, until recently, the identification of the molecular intermediates involved in GPCR endocytosis and resensitization has been less forthcoming. Surprisingly, it was found that the same proteins contributing to the desensitization of GPCR responsiveness, GRKs and $\beta$-arrestins, also contribute to GPCR sequestration (2632). The involvement of GRK-mediated phosphorylation in GPCR sequestration was first demonstrated for the $\mathrm{m} 2 \mathrm{mAChR}$ (27). These results initially conflicted with earlier data obtained using $\beta_{2}$ ARs lacking their putative sites for both GRK- and PKA-mediated phosphorylation which sequestered normally in Chinese hamster ovary cells (33). However, using a $\beta_{2}$ AR-Y326A mutant, which neither sequestered nor resensitized, a role for GRK-mediated phosphorylation in the sequestration of the $\beta_{2} \mathrm{AR}$ was also established (28). Moreover, it was shown that in human embryonic kidney (HEK 293) cells the sequestration of a $\beta_{2} A R$ lacking putative sites for GRK- but not PKA-mediated phosphorylation was impaired by $50 \%$ (28). Nonetheless, the observation that $\beta_{2} \mathrm{ARs}$ lacking putative sites for phosphorylation still exhibited a capacity for sequestration indicated that, while GRK-mediated phosphorylation facilitated the sequestration of the $B_{2} \mathrm{AR}$, it 
was not absolutely required. Rather, GRKmediated phosphorylation promoted the binding of $B$-arrestins which are absolutely required for $\beta_{2} A R$ sequestration (29). $B$ Arrestins bind to GPCRs, uncouple them from their cognate heterotrimeric $G$ protein and target them specifically for dynamindependent clathrin-coated vesicle-mediated endocytosis (26). The targeting of $\beta$-arrestinbound receptors to coated pits appears to involve an interaction between the carboxylterminal domains of $\beta$-arrestin1 and $\beta$ arrestin2 with the globular head of the clathrin-heavy chain (34-36). The other two members of the arrestin family, visual arrestin and cone arrestin, appear to lack the clathrinbinding motif and therefore do not support GPCR endocytosis (34).

\section{Down-regulation}

Receptor down-regulation involves a loss in the total cellular complement of particular GPCR in response to prolonged or repeated agonist stimulation. Down-regulation occurs as the consequence of both increased lysosomal degradation of pre-existing receptors and reduced mRNA and protein synthesis (37-40). PKA not only contributes to GPCR desensitization by phosphorylating receptors, but in the case of $\beta_{2} \mathrm{AR}$, PKA activation leads to a decrease in steady-state $\beta_{2} A R$ mRNA levels (38). It is uncertain whether receptor sequestration represents the initial step in the lysosomal degradation of GPCRs following long-term agonist exposure. It is possible that, while the majority of sequestered receptors are recycled back to the plasma membrane, a small fraction of the internalized receptors are sorted in endosomes for degradation in lysosomes (41). This hypothesis is supported by a recent study indicating that the overexpression of $B$-arrestin sequestration dominant-negatives reduces the rate of $\beta_{2} A R$ down-regulation (42). Alternatively, GPCRs are targeted for degradation via a distinct endocytic path- way. Evidence for a distinct pathway comes from the mutation studies where receptor mutants have been identified which do not sequester, but down-regulate more efficiently (25) as well as receptor mutants that do not down-regulate but sequester normally (43). Moreover, tyrosine residues located in the carboxyl-terminal tail of the $\beta_{2} \mathrm{AR}$ have been implicated in receptor down-regulation but not sequestration (37).

\section{Use of green fluorescent protein to study GPCR regulation}

A great deal of knowledge has accumulated concerning the mechanisms by which GPCRs signal and desensitize. However, by virtue of the nature of the membrane-delineated environment in which GPCRs reside, their study has required laborious biochemical techniques. The introduction of foreign epitope tags into the cDNAs encoding GPCRs has facilitated the study of both GPCR phosphorylation and endocytosis. This has been particularly important for receptor systems for which good radio-ligands and antibodies have not been available or are prohibitively expensive. The recent introduction of the jellyfish Aqueora victoria GFP for use as an autofluorescent epitope tag (44) has allowed the visualization of GPCRs and their regulatory proteins in real-time with a precision not afforded by fluorescent antibody staining of fixed cells. The ability of GFP to allow real-time visualization of proteins in living cells now allows us to effectively assess how both agonist and/or the overexpression of dominant-negative proteins affect changes in the dynamic distribution of both GPCRs and their regulatory proteins.

\section{Receptor-G FP conjugates}

To date GFP has been used to epitope tag three distinct GPCRs, the cAMP chemoattractant protein receptor (CAR1) in Dictostelium discoideum, the $\mathrm{B}_{2} \mathrm{AR}$ and the chole- 
cystokinin type A receptor (CCKAR) (4548). These receptor-GFP conjugates have been used to begin to answer several questions that cannot be adequately addressed by immunofluorescence in fixed cell preparations. Xiao et al. (45) examined the distribution of CAR1 in living cells undergoing cAMP-directed migration. Time-lapse imaging of individual cells showed that CAR1 remains evenly distributed on the cell surface of a cell and all its projections during chemotaxis. Moreover, pseudopods at migration fronts showed transiently reduced fluorescent signals suggesting that the movement of the receptors into these zones lagged the protrusion process. The addition of GFP to the carboxyl-terminal tail of the $\beta_{2} \mathrm{AR}$ results in a receptor that is fully functional with respect to all its measurable parameters (e.g., G protein-coupling, receptor sequestration and agonist-dependent phosphorylation) and in fact appears to be better coupled to adenylyl cyclase than the wild-type receptor (46). Using the GFP-tagged $B_{2} A R$, we showed that the diffusion rate for the $\beta_{2} A R$ is consistent with the free diffusion rates found for other membrane proteins as the low density lipoproteins, indicating that their diffusibility following agonist-mediated $\beta$-arrestin desensitization would not be a limiting step in receptor endocytosis (46). Moreover, it was found that in living cells the $\beta_{2} \mathrm{AR}-\mathrm{GFP}$ conjugate internalized to endosomes and that within 15 min could be found in more complicated structures formed from the fusion of multiple endosomes. Perhaps the most interesting data generated using a GFP-tagged GPCR come from studies of a CCKAR-GFP conjugate (49). When expressed in different cell lines this receptor exhibited different properties of endocytosis. In CHO, COS-1 and HeLa cells the CCKAR-GFP internalizes in an agonist-dependent manner, whereas in NIH3T3 the receptor constitutively endocytoses. The constitutive endocytosis of the receptor could be prevented by antagonist treatment of the cells. Interest- ingly, unlike the $\beta_{2} \mathrm{AR}$, the CCKAR-GFP internalizes to endosomes but is not targeted to lysosomes for degradation (46-48). The apparent differences in the compartmentalization of the CCKAR and the $\beta_{2} \mathrm{AR}$ highlight the utility of GFP as a tool to pinpoint receptor-specific differences in GPCR regulation.

\section{GPCR regulatory protein-GFP conjugates}

In addition to coupling GFP to GPCRs, it has been possible to couple GFP to both GRK2 and $\beta$-arrestin 2 without affecting their normal function as GPCR regulatory proteins $(21,49)$. The conjugation of GFP to the carboxyl-terminus of $\beta$-arrestin 2 has greatly facilitated our ability to assess both the normal distribution of $B$-arrestin2 in cells and the redistribution of $\beta$-arrestin 2 to the plasma membrane in response to agonist activation (49). B-arrestin2 GFP not only supported $\beta_{2}$ AR endocytosis, but was easily observed to redistribute in a time- and agonist dosedependent manner consistent with the pharmacological characteristics of $B_{2} A R$ sequestration (49; Ferguson SSG and Caron MG, unpublished observations). Moreover, $\beta$ arrestin2 GFP translocation was GRK-dependent (49). Because both GRK-mediated phosphorylation and $B$-arrestin binding to GPCRs represent a divergent step in the GPCR signaling and desensitization cascades, this B-arrestin2 GFP translocation assay represents a potentially powerful universal methodology for screening orphan receptors, GRK inhibitors and novel GPCR ligands. An additional advantage of $B$-arrestin2 GFP is that this technique offers the potential to examine: 1) the agonist specificity of receptor $\beta$-arrestin/receptor interactions, 2) whether $\beta$-arrestins endocytose with receptors in endocytic vesicles, 3) how drug treatments affect $B$-arrestin/receptor interactions and 4) the mechanisms regulating the dissociation of the GPCR/ß-arrestin endocytic complex. 


\section{Conclusion}

The dual function of GRKs and arrestins in the regulation of both the desensitization and resensitization of GPCRs highlights the complexity of the GPCR signal transduction system. It is now clear that GPCR regulatory processes that were traditionally considered to be mediated by distinct mechanisms have now been shown to exhibit considerable overlap. This is particularly true of $\beta$ - arrestins which when overexpressed re-establish the resensitization phenotype of mutant receptors impaired in their ability to resensitize (50). The use of both GPCR- and B-arrestin-GFP constructs to examine the effects of both agonist and antagonists on the activity and intracellular processing of GPCRs is expected to contribute to the development of new strategies to treat diseases associated with perturbations in GPCR function.

\section{References}

1. Neer EJ (1995). Heterotrimeric G proteins: Organizers of transmembrane signals. Cell, 80: 249-257.

2. Parma J, Duprez L, Van Sande J, Cochaux P, Geny C, Mockel J , DumontJ \& Vassart $G$ (1993). Somatic mutations in the thyrotropin receptor gene cause hyperfunctioning thyroid adenomas. Nature, 365: 649-651.

3. Robinson PR, Cohen GB, Zhukovsky EA \& Oprian DD (1992). Constitutively active mutants of Rhodopsin. Neuron, 9: 719725.

4. Shenker A, Laue L, Kosugi S, Merendino J rJ J , Minegishi T \& Cutler J r GB (1993). A constitutively activating mutation of the luteinizing hormone receptor in familial male precocious puberty. Nature, 365: 652-654.

5. Ungerer M, Böhm M, Elce J S, Erdmann E \& Lohse MJ (1993). Altered expression of $ß$-adrenergic receptor kinase and $B_{1}$-adrenergic receptors in the failing heart. Circulation, 87: 454-463.

6. Ungerer $M$, Parruti G, Böhm M, Puzicha M, De Blasi A, Erdmann E \& Lohse MJ (1994). Expression of $B$-arrestins and $B$ adrenergic receptor kinases in the failing human heart. Circulation Research, 74: 206-213.

7. Terwilliger RZ, Oritiz J , Guitart X \& Nestler EJ (1994). Chronic morphine administration increases $ß$-adrenergic receptor kinase (BARK) levels in the rat locus coeruleus. J ournal of Neurochemistry, 63: 1983-1986.

8. Gros R, Benovic J L, Tan CM \& Feldman RD (1997). G-protein-coupled receptor kinase is increased in hypertension. J ournal of Clinical Investigation, 99: 2087-2093.

9. Lefkowitz RJ (1993). G protein-coupled receptor kinases. Cell, 74: 409-412.
10. Ferguson SSG, Barak LS, Zhang J \& Caron MG (1996). G-protein-coupled receptor regulation: role of G-protein-coupled receptor kinases and arrestins. Canadian J ournal of Physiology and Pharmacology, 74: 1095-1110.

11. Ferguson SSG, Zhang J, Barak LS \& Caron MG (1997). Pleiotropic role for GRKs and $B$-arrestins in receptor regulation. News in Physiological Sciences, 12: 145-151.

12. Benovic J L, Kühn H, Weyland I, Codina J , Caron MG \& Lefkowitz RJ (1987). Functional desensitization of the isolated $B$ adrenergic receptor by the $B$-adrenergic receptor kinase: Potential role of an analog of the retinal protein arrestin $(48-\mathrm{kDa}$ protein). Proceedings of the National Academy of Sciences, USA, 84: 8879-8882.

13. Lohse MJ, Benovic J L, Codina J, Caron MG \& Lefkowitz RJ (1990). B-arrestin: A protein that regulates $B$-adrenergic receptor function. Science, 248: 1547-1550.

14. Attramadal $\mathrm{H}$, Arriza J L, Aoki C, Dawson TM, Codina J , Kwatra MM, Snyder SH, Caron MG \& Lefkowitz RJ (1992). ßarrestin2, a novel member of the arrestin/ B-arrestin gene family. J ournal of Biological Chemistry, 267: 17882-17890.

15. Lohse MJ, Andexinger S, Pitcher J, Trukawinski S, Codina J , Faure J -P, Caron MG \& Lefkowitz RJ (1992). Receptor specific desensitization with purified proteins. Kinase dependence and receptor specificity of $B$-arrestin and arrestin in the $\beta_{2^{-}}$ adrenergic receptor and rhodopsin systems. J ournal of Biological Chemistry, 267: 8558-8564.

16. Premont RT, Inglese J \& Lefkowitz RJ (1995). Protein kinases that phosphorylate activated $G$ protein-coupled receptors. FASEB J ournal, 9: 175-182.

17. Inglese J , Glickman J F, Lorenz W, Caron
MG \& Lefkowitz RJ (1992). Isoprenylation of a protein kinase. Requirement of farnesylation/ $\alpha$-carboxyl methylation for full enzymatic activity of rhodopsin kinase. J ournal of Biological Chemistry, 267: 1422-1425.

18. Pitcher J A, Inglese J, Higgins J B, Arriza J L, Casey PJ , Kim C, Benovic J L, Kwatra MM, Caron MG \& Lefkowitz RJ (1992). Role of $B \gamma$ subunits of $G$ proteins in targeting the $ß$-adrenergic receptor kinase to membrane-bound receptors. Science, 257: 1264-1267.

19. Premont RT, Koch WJ, Inglese J \& Lefkowitz RJ (1994). Identification, purification and characterization of GRK5, a member of a family of $\mathrm{G}$ protein-coupled receptor kinases. J ournal of Biological Chemistry, 269: 6832-6841.

20. Stoffel RH, Randall RR, Premont RT, Lefkowitz RJ \& Inglese J (1994). Palmitoylation of $\mathrm{G}$ protein-coupled receptor kinase, GRK6. Lipid modification diversity in the GRK family. J ournal of Biological Chemistry, 269: 27791-27794.

21. Pitcher J A, Hall RA, Daaka Y, Zhang J, Ferguson SSG, Hester S, Miller S, Caron MG, Lefkowitz RJ \& Barak LS (1998). The $G$ protein-coupled receptor kinase 2 is a microtubule-associated protein kinase that phosphorylates tubulin. J ournal of Biological Chemistry, 273: 12319-12324.

22. Yu SS, Lefkowitz RJ \& Hausdorff WP (1993). B-Adrenergic receptor sequestration. A potential mechanism of receptor resensitization. J ournal of Biological Chemistry, 268: 337-341.

23. Pippig $S$, Andexinger $S \&$ Lohse $M J$ (1995). Sequestration and recycling of $B_{2-}$ adrenergic receptors permit resensitization. Molecular Pharmacology, 47: 666676. 
24. Sibley DR, Strasser RH, Benovic J L, Daniel K \& Lefkowitz RJ (1986). Phosphorylation/dephosphorylation of the ß-adrenergic receptor regulates its functional coupling to adenylate cyclase and subcellular distribution. Proceedings of the $\mathrm{Na}-$ tional Academy of Sciences, USA, 83: 9408-9412.

25. Barak LS, Tiberi M, Freedman NJ , Kwatra MM, Lefkowitz RJ \& Caron MG (1994). A highly conserved tyrosine residue in Gprotein-coupled receptors is required for agonist-mediated $ß_{2}$-adrenergic receptor sequestration. J oumal of Biological Chemistry, 269: 2790-2795.

26. Zhang J Ferguson SSG, Barak LS, Menard L \& Caron MG (1996). Dynamin and Barrestin reveal distinct mechanisms for $G$ protein-coupled receptor internalization. J ournal of Biological Chemistry, 271: 18302-18305.

27. Tsuga H, Kameyama K, Haga T, Kurose H $\&$ Nagao T (1994). Sequestration of muscarinic acetylcholine receptor $\mathrm{m} 2$ subtypes. Facilitation by $\mathrm{G}$ protein-coupled receptor kinase (GRK2) and attenuation by a dominant-negative mutant of GRK2. J ournal of Biological Chemistry, 269: 32522-32527.

28. Ferguson SSG, Menard L, Barak LS, Koch WJ , Colapietro A-M \& Caron MG (1995). Role of phosphorylation in agonist promoted $ß_{2}$-adrenergic receptor sequestration. Rescue of a sequestration-defective mutant receptor by ßARK1. J oumal of Biological Chemistry, 270: 24782-24789.

29. Ferguson SSG, Downey III WE, Colapietro A-M, Barak LS, Menard L \& Caron MG (1996). Role of ß-arrestin in mediating agonist-promoted $\mathrm{G}$ protein-coupled receptor internalization. Science, 271: 363366.

30. Aramori I, Ferguson SSG, Bieniasz PD, Zhang J, Cullen BR \& Caron MG (1997). Molecular mechanism of desensitization of the chemokine receptor CCR-5: receptor signaling and internalization are dissociable from its role as an HIV-1 coreceptor. EMBO J ournal, 16: 4606-4616.

31. Itokawa $\mathrm{N}$, Toru $\mathrm{M}$, Ito $\mathrm{K}$, Tsuga $\mathrm{H}$, Kameyama K, Haga T, Arinam T \& Hamaguchi $H$ (1996). Sequestration of the short and long isoforms of dopamine $D_{2}$ receptors expressed in Chinese hamster ovary cells. Molecular Pharmacology, 49: 560-566.

32. Schlador ML \& Nathanson NM (1997). Synergistic regulation of $\mathrm{m} 2$ muscarinic acetylcholine receptor desensitization and sequestration by $\mathrm{G}$ protein-coupled receptor kinase-2 and B-arrestin-1. J ournal of Biological Chemistry, 272: 18882-18890.

33. Bouvier M, Hausdorff WP, De Blasi A, O'Dowd BF, Kobilka BK, Caron MG \& Lefkowitz RJ (1988). Removal of phosphorylation sites from the $\beta_{2}$-adrenergic receptor delays the onset of agonist-promoted desensitization. Nature, 333: 370373.

34. Goodman J r OB, Krupnick J G, Santini F, Gurevich W, Penn RB, Gagnon AW, Keen J H \& Benovic J L (1996). B-Arrestin acts as a clathrin adaptor in endocytosis of the $B_{2}$-adrenergic receptor. Nature, 383: 447450.

35. Goodman J r OB, Krupnick J G, Gurevich W, Benovic J L \& Keen J H (1997). Arrestin/clathrin interaction: Localization of the arrestin binding locus to the clathrin terminal domain. J ournal of Biological Chemistry, 272: 15017-15022.

36. Krupnick J G, Goodman J r OB, Keen J H \& Benovic J L (1997). Arrestin/clathrin interaction: Localization of the clathrin binding domain of nonvisual arrestins to the carboxyl terminus. J ournal of Biological Chemistry, 272: 15011-15016.

37. Valiquette $M$, Bonin $H$, Hnatowich $M$, Caron MG, Lefkowitz RJ \& Bouvier M (1990). Involvement of tyrosine residues located in the carboxyl tail of the human $B_{2}$-adrenergic receptor in agonist-induced down-regulation of the receptor. Proceedings of the National Academy of Sciences, USA, 87: 5089-5093.

38. Bouvier M, Collins S, O'Dowd BF, Campbell PT, de Blasi A, Kobilka BK, MacGregor C, Irons G, Caron MG \& Lefkowitz RJ (1989). Two distinct pathways for CAMP-mediated down-regulation of the $\mathrm{B}_{2}$-adrenergic receptor. Phosphorylation of the receptor and regulation of its mRNA level. J ournal of Biological Chemistry, 264: 16786-16792.

39. Doss RC, Perkins J P \& Harden TK (1981). Recovery of ß-adrenergic receptors following longterm exposure of astrocytoma cells to catecholamine. J ournal of Biological Chemistry, 256: 12281-12286.

40. Hadcock J R \& Malbon CC (1988). Down regulation of ß-adrenergic receptors: agonist-induced reduction in receptor mRNA levels. Proceedings of the National Academy of Sciences, USA, 85: 5021-5025.

41. von Zastrow M \& Kobilka BK (1992). Ligand-regulated internalization and recycling of human $B_{2}$-adrenergic receptors between the plasma membrane and endosomes containing transferrin receptors. J ournal of Biological Chemistry, 267: 3530-3538.

42. Gagnon AW, Kallal L \& Benovic J L (1998). Role of clathrin-mediated endocytosis in agonist-induced down-regulation of $\mathrm{B}_{2}$ adrenergic receptor. J ournal of Biological Chemistry, 273: 6976-6981.

43. Campbell PT, Hnatowich M, O'Dowd BF, Caron MG \& Lefkowitz RJ (1991). Mutations in the human $\aleph_{2}$-adrenergic receptor that impair coupling to $\mathrm{G}_{\mathrm{S}}$ interfere with receptor down-regulation but not sequestration. Molecular Pharmacology, 39: 192198.

44. Cubit AB, Heim R, Adams SR, Boyd AE, Gross LA \& Tsien RY (1995). Understanding, improving and using green fluorescent proteins. Trends in Biochemical Sciences, 17: 416-421.

45. Xiao Z, Zhang N, Murphy DB \& Deverotes PN (1997). Dynamic distribution of chemoattractant receptors in living cells during chemotaxis and persistent stimulation. J ournal of Cell Biology, 139: 365374.

46. Barak LS, Ferguson SSG, Zhang J, Martenson C, Meyer $T \& \&$ Caron MG (1997). Internal trafficking and surface mobility of a functionally intact $\beta_{2}$-adrenergic receptor-green fluorescent protein conjugate. Molecular Pharmacology, 51: 177-184.

47. Kallal L, Gagnon AW, Penn RB \& Benovic $J \mathrm{~L}$ (1998). Visualization of agonist-induced sequestration and down-regulation of a green fluorescent protein-tagged $\beta_{2}$-adrenergic receptor. J ournal of Biological Chemistry, 272: 322-328.

48. Tarasova NI, Stauber RH, Choi J K, Hudson EA, Czerwinski G, Miller J L, Pavlakis GN, Michejda CJ \& Wank SA (1997). Visualization of $\mathrm{G}$ protein-coupled receptor trafficking with the aid of the green fluorescent protein. Endocytosis and recycling of cholecystokinin receptor type A. J ournal of Biological Chemistry, 272: 1481714824.

49. Barak LS, Ferguson SSG, Zhang J \& Caron MG (1997). A ß-arrestin/green fluorescent protein biosensor for detecting $\mathrm{G}$ proteincoupled receptor activation. J ournal of Biological Chemistry, 272: 27497-27500.

50. Zhang J , Barak LS, Winkler KE, Caron MG \& Ferguson SSG (1997). A central role for $ß$-arrestins and clathrin-coated vesiclemediated endocytosis in $B_{2}$-adrenergic receptor resensitization. J ournal of Biological Chemistry, 272: 27005-27014. 


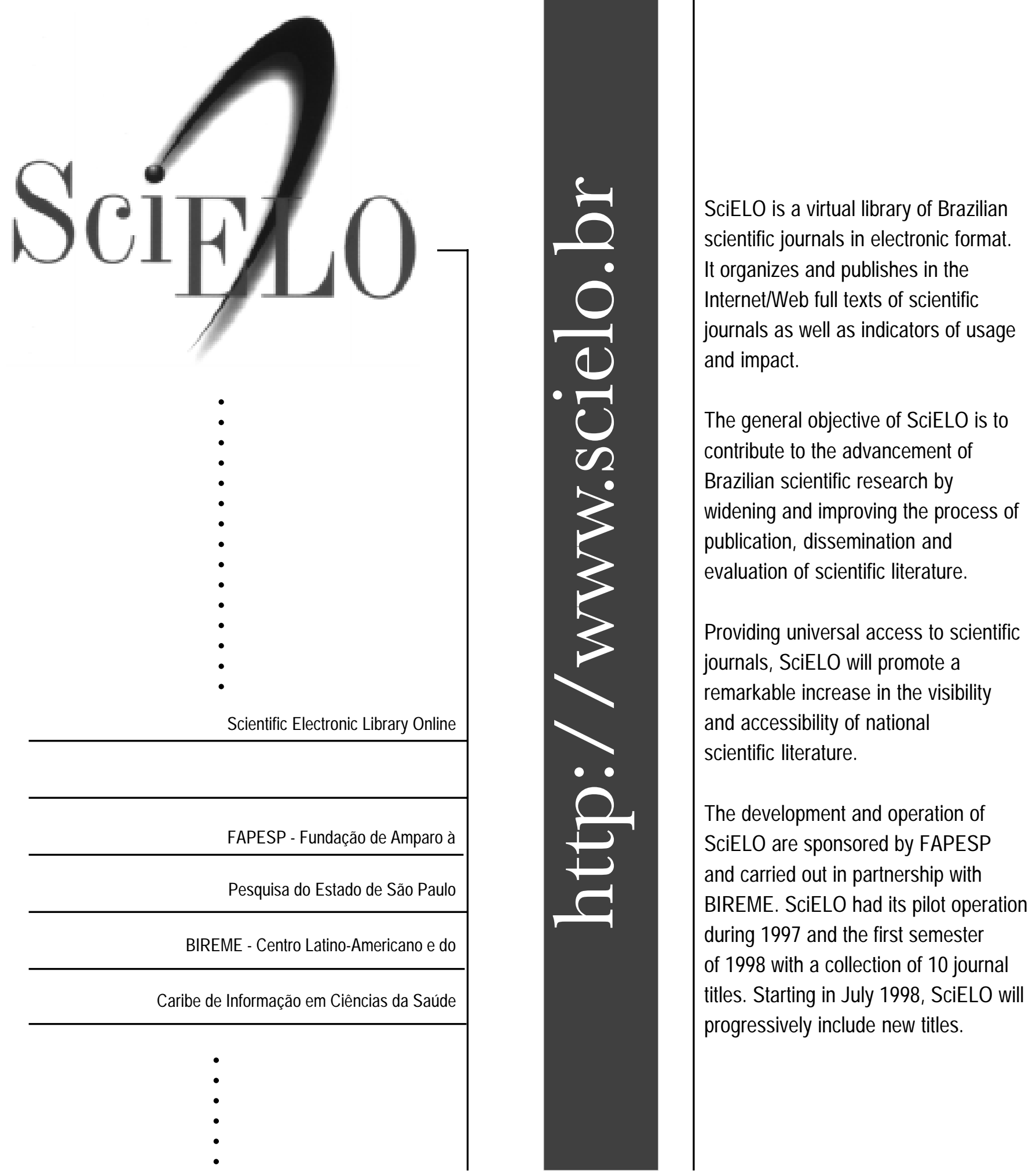

